International Journal of Production Research, Vol. 42, Issue 10 May 2004, Pages 2063-2081

\title{
Implications of Form Postponement \\ to Manufacturing: a Cross Case Comparison
}

\author{
Authors: \\ Dr Heather Skipworth * (heather.skipworth@cranfield.ac.uk) \\ Prof Alan Harrison (a.harrison@cranfield.ac.uk)
}

*corresponding author

Fax no 01234751712

Cranfield School of Management

Cranfield University

Cranfield

Bedford

MK43 0AL 


\title{
Implications of Form Postponement to Manufacturing: \\ a Cross Case Comparison
}

\begin{abstract}
While much is written in the literature about the benefits and strategic impact of form postponement (FPp), little is still known about its application. We address 'how' FPp is applied in terms of its operational and logistics implications within manufacturing facilities. This paper is a retrospective study of the application of FPp in three diverse manufacturing environments: a manufacturer of specialist high voltage cabling equipment we call 'Electrico'; a manufacturer of industrial electric motors we call 'Motorco'; and a manufacturer of control systems and components mainly for automated telling machines we call 'Controlco'.
\end{abstract}

Our findings show that FPp improved responsiveness of manufacturing in all cases, but that none of the applications of FPp was ideal from a theoretical perspective. The production planning system must be both responsive and flexible to support the application. For highly customised products, the customer order decoupling point (CODP) must be located sufficiently upstream in the manufacturing process to avoid removal of components and time- consuming modifications. We present conclusions from all three studies, including an inventory management decision framework for FPp and a framework for the application of FPp which encompasses a number of practical considerations. 


\section{Keywords}

Form postponement; responsiveness, customization; decoupling point 


\section{Introduction}

Markets are increasingly characterized by uncertainty of demand and supply, and by mass customization of products to meet individual needs. Uncertainty has been reviewed by Yang et al (2004), and mass customization by Mikkola and SkjpttLarsen (2004). Both sets of authors position postponement as an enabler to meeting the operational and logistics challenges that are presented. However, 'little is still known about the implementation of postponement' (Yang and Burns, 2003). We have focused specifically on form postponement (FPp), which we define as:

'....the delay, until customer orders are received, of the final part of the transformation processes, through which the number of different items (stock keeping units) proliferates, and for which only a short time period is available. The postponed transformation processes may be manufacturing processes, assembly processes, configuration processes, packaging, or labelling processes'.

So far, we have contributed two papers to this journal which help to throw light on issues of implementation of FPp. Our first study (Skipworth and Harrison, 2004) featured a manufacturer of specialist high voltage cabling equipment which we called 'Electrico'; the second was a manufacturer of industrial electric motors we called 'Motorco' (Skipworth and Harrison, 2006). In addition to describing the cases and the results of our investigations in each, these papers provide our conceptual model of FPp, together with a review of relevant literature which we do not repeat in this paper.

Here, we report a third case study at 'Controlco', where the product was specifically designed for FPp, unlike the cables at Electrico and the motors at Motorco. Instead 
the FPp regime was applied to an existing product range previously engineered to order (ETO) or made to order (MTO). Second, we compare our findings from all three studies across the operational implications within the manufacturing facility such as inventory management strategy, product design, production variety, and production scheduling. Also, we compare the impact of FPp on common performance metrics, including delivery reliability, order lead-time, demand amplification, capacity utilisation, and throughput efficiency. Finally, we develop conclusions from a crosscase comparison of all three studies. Our conclusions include an inventory management decision framework for FPp and a framework for applying FPp - which encompasses a number of practical considerations such as guidelines for positioning the customer order decoupling point (CODP). The CODP decouples forecast-driven operations that are run in anticipation of customer orders, and order-driven operations that are based on customer orders (van Hoek, 2001).

\section{Research Design}

We sought to address the question 'how is FPp applied in manufacturing'. We also addressed the motivation for applying FPp, and the impact it has on various performance metrics - particularly those related to customer service. The six propositions we sought to test were taken from our theoretical framework (shown in table 1) as indicated by the shaded areas and the labels P1 to P6. These propositions arose from a consideration of the research questions, the FPp conceptual model, and a literature review (Skipworth and Harrison, 2004). In summary, they are:

What is the demand profile of products selected for manufacture under FPp? 
P1: Products are selected for manufacture under FPp rather than MTS when they exhibit high demand mix, high demand variability, and low volume demand at finished product level.

P2: Products are selected for manufacture under FPp rather than ETO when they exhibit high volume demand at generic product level.

What is the impact on customer service of FPp?

P3: FPp considered as an alternative to MTS increases ex-stock availability.

P4: FPp considered as an alternative to ETO reduces order lead-times and increases delivery reliability but introduces demand amplification.

What are the product design implications of applying FPp?

P5: Product families subject to FPp will have a higher level of standardization and modularity than product families subject to ETO

What are the manufacturing planning and scheduling implications of applying FPp?

P6: Capability of the postponed transformation process to respond to high demand variability requires excess capacity and high throughput efficiency

Each proposition compares FPp with either ETO or MTO and MTS regimes across a number of characteristics and suggests that differences will be measurable across the three regimes.

\section{Table 1: Theoretical framework illustrating the propositions}

The Electrico case study (Skipworth and Harrison, 2004) addressed a product (high voltage cabling) which was configured rather than customised. The 'Motorco' study (Skipworth and Harrison, 2006) focused on an FPp regime applied to Large Direct Current (LDC) motors. These are relatively complex products that were highly customised and therefore produced in high variety. Our third study at Controlco examined the application of FPp to the manufacture of encrypted pin pads (destined for automatic telling machines) which were designed to be manufactured by FPp. 


\subsection{Within Case Comparison of Different Regimes}

In order to test the above propositions, it was necessary to compare the three approaches to production (we refer to these as 'regimes') within the same operating facility and for the same time period. These regimes (ETO or MTO, MTS and FPp) became our units of analysis (UoA's). The advantage of this research design was to screen out contextual differences between operating facilities that would not have been relevant to our study. Table 2 summarises the UoA's used in each case. UoA's for the three case studies were as follows:

- Electrico: the three UoA's were all the same cable group dictated by customer rather than product group.

- Motorco: the ETO UoA consisted of different LDC motors to those encompassed by the FPp and MTS UoAs - which were both based on the UK standard motor specifications.

- Controlco: keypad products were selected for both the FPp and MTO UoA's. However, a different product (a pushbutton body) was selected for the MTS UoA because no keypads were MTS.

\section{Table 2: Comparison of the UoAs used in the three case studies}

The net result was that the three UoA's within each case study compared products of very similar design. This ensured that the comparison between the different approaches (FPp, MTO and MTS), in terms of the various measures, screened out product-specific factors. The only exception was the MTS UoA in the Controlco case - this was not a keypad product like the FPp and MTO UoA's. However the complexity of the product and the manufacturing processes were very similar to the keypads. We took this exception into account. 


\subsection{Data Collection}

Evidence was collected across a number of production characteristics, explained in more detail in our earlier paper (Skipworth \& Harrison, 2006) and summarised here:

Demand: external demand was quantified from the customer order ex-works due dates and quantities. Three measures of demand were taken for each case: demand mix (number of variants), average volume at both generic and end item level, and variability of demand. Coefficient of variation (CV) was used as a measure of weekly demand variability.

Demand Amplification: this was mapped for a single member of the supply chain (Bicheno 1998). External customer orders (demand imposed on the manufacturing system) and orders placed at each manufacturing stage (the manufacturing process schedule) were plotted against time.

Customer service measures: Order lead-time was recorded between customer placing the order and receiving it. Delivery reliability compared delivery date and quantity with the due date, to establish if the delivery was made on-time in-full (OTIF). Exstock availability measured the proportion of orders and enquiries for which the correct stock (finished or generic) was available.

Product standardization: we used Collier's $(1981,1982)$ commonality index to measure the average number of common parent items per distinct component part, or as we prefer, the average number of incidences of the distinct component parts in a set of parent items. 
Product Modularity: this is a relative property - products cannot be classified as either modular or not but rather exhibit more or less modularity in design. We used a measure based on the similarity between the physical and functional architectures of the design (Ulrich, 1994).

Excess Capacity: is the percentage amount that available capacity exceeds demand and was indicated by capacity utilisation and design capacity levels.

Throughput efficiency: is the time taken for value adding activities to be performed on a typical batch quantity ('value added time'), as a proportion of the time the factory was available to add value ('elapsed time' - New 1993).

Production Variety: this maps the number of physically different items against the average process lead time.

Van Hoek (2001) observes that 'triangulation [in postponement research] requires a comprehensive, coherent and carefully integrated research design'. By developing a broad-based set of measures, we collected and analysed evidence using both the triangulation of methods and the triangulation of data sources. In order to ensure the validity of within case comparisons between different regimes, we collected data for each regime for customer orders due for delivery within the same period.

Taped interviews were used to collect qualitative data. These interviews included both structured and open-ended questions, which explored the views of informants who were selected for their knowledge and experience of a given process. Evidence from the taped interviews was corroborated by documentary, archival or database evidence. 


\section{Analysing the Form Postponement Applications in Context}

Here, we compare the contexts of the three cases, describe the FPp applications and report the main flaws in these applications.

\subsection{Contextual Considerations}

The three products made under FPp were all industrial products manufactured by medium sized companies in England (120 to 200 employees). All three products exhibited 'component swapping' modularity (Pine, 1993) where 'different components are paired with the same basic product' to provide high variety in the finished product. All three companies manufactured and stocked the generic or basic product (Electrico: laid up cable, Motorco: standard motor, Controlco: unconfigured keypad) and then combined them with differentiating components in the postponed process.

Table 3: Cross-case comparison of contextual data relating to the FPp applications

The three cases of FPp were otherwise very different, as the data in table 3 illustrates. The products varied in complexity, as the number of distinct components illustrates. Cables made by Electrico were simple products whereas motors made at Motorco were more complex, requiring on average 160 distinct components and frequently in excess of 200 .

Volume versus variety: EPP keypads manufactured by Controlco were mass customised for the High Street banks. The keypads exhibited high variety at finished product level and high volume at generic product level. Motors subject to FPp at Motorco were manufactured in similar variety but at very low volumes - even at 
generic product level. Electrico cables, though produced in high volumes, exhibited an unexpectedly low level of variety - far below their potential variety..

Manufacturing Process: Manufacturing processes at the three facilities reflected product diversity, as illustrated by the total value added process times -37 hours for a motor compared to 9 minutes for a keypad!

- Electrico: manufacturing was semi continuous in that length - rather than discrete parts - was manufactured. Also, cable making was entirely equipment driven and organised as a batch process.

- Motorco: a variety of machines was employed in a broad range of processes (such as soldering, machining and curing) and organised into process cells.

- Controlco: only simple manual assembly processes requiring a few gluing machines and a lasering machine were conducted.

Reasons for applying FPp: In all three cases FPp was seen as an alternative to MTO/ETO. MTS was not considered an option for products subject to FPp. Accordingly FPp was applied to reduce the order lead-time achieved by MTO/ETO and thereby improve responsiveness. In the case of Electrico there was a need to improve the match between cable supply and their biggest customer's demand, and to avoid the 'feast and famine' supply experienced with MTO. At Motorco, UK customers expected that motors based on a standard specifications would be available on a 3 to 4 week lead-time - not the 10 to 14 weeks achieved by ETO. 
The only product to be specifically designed for "last minute configuration" (FPp) was Controlco's EPP keypad. The design sought to improve responsiveness of supply to their biggest customer without incurring the high component stocks that had plagued the previous keypad range.

\subsection{The Form Postponement Applications}

Here, we compare the application of FPp in terms of product and customer selection, inventory management and manufacturing planning. Highlights are presented in table 4.

Selection of products and customers: In both Electrico and Controlco cases, FPp was applied exclusively to products for their biggest customers - providing them with enhanced responsiveness.

- Electrico: the restriction to one customer was artificial - FPp could have been equally well applied to many other cables.

- Controlco: the EPP keypad was designed and manufactured exclusively for their biggest customer.

- Motorco: the products to be subject to FPp were selected at the generic level (30 UK standard motors) and any motor variants based on these standard specifications were subject to FPp regardless of customer.

Table 4: Cross-case comparison of the 'change content' data for the FPp applications.

At Electrico, only the high volume finished cable items were selected. Thus for a given generic cable some finished cable variants were subject to FPp whilst others 
(with only a different sheath colour) were supplied under MTO. This further unnecessary restriction was because the sheathing polymer supplied into the postponed process was required on consignment stock to ensure its availability within 24 hours whilst postponing procurement of the polymer until consumption.

Motorco and Controlco did not have this problem with the supply of components into the postponed process. Motorco did not provide such a responsive supply to customers and therefore time was available to make or purchase many modification components to order. Controlco required immediate availability of keytips for the postponed keypad configuration; these were made in-house to kanbans, so volume was not a major issue.

Inventory Management: Order promising at Motorco was based on modification and part availability, so quoted lead-times were long and variable. This was attributable to the highly customised nature of the motors - customers were free to choose any customising components. In contrast at Electrico and Controlco the confinement of FPp to predefined customising options enabled a standard order lead-time to be offered.

At Motorco customer orders were communicated by either hard copy purchase orders or by fax on an ad hoc basis. At Electrico customer orders were communicated by fax every Tuesday. At Controlco, customer orders were communicated by EDI every morning at 9:00 am and Controlco sales administrators processed orders immediately.

Manufacturing Planning: All three firms employed MRP systems driven by fixed period master scheduling for planning and control. At Controlco and Motorco the 
MRP systems were compiled nightly. At Electrico the MRP system was compiled weekly (it required two days for compilation) restricting the customer to placing weekly orders every Tuesday. At Motorco and Controlco, released manufacturing orders were downloaded from MRP to the shopfloor nightly and three times daily, but weekly at Electrico. Despite the responsive nature of manufacturing planning systems at Motorco and Controlco, customer orders for products subject to FPp by-passed MRP.

At Motorco it had not been possible to set up the MRP system to process the proliferation of postponed modifications due to lack of flexibility in the BOMs. Therefore special instruction sheets were established to control modifications and associated materials. Parts acquisition for modifications was cited as a laborious procedure involving manual stock checks and hand written purchase requisitions. From a material control perspective, Motorco would have benefited from configurable BOMs.

At Controlco manufacturing orders subject to MTO were raised by sales, simultaneously released to the factory three times per day. This ensured a maximum delay of 8 hours between order creation and availability for manufacture. This was not considered responsive enough for EPP keypad orders subject to FPp. Once communicated by EDI, these orders were logged on the manufacturing order system, hard copies printed and manually transferred to the shopfloor -1.5 hours from order receipt to availability for manufacture. 


\subsection{Major Flaws in the Form Postponement Applications}

None of the three FPp applications we studied was ideal. The application at Electrico was so flawed that it was eventually abandoned. The application at Motorco incurred unnecessary manufacturing costs, although it was sustainable and offered benefits compared with MTO. At Controlco the FPp application was not as originally envisaged from the customer's sales forecast. The flaws in each of the FPp applications, a brief description of the ideal applications and the potential benefits are discussed in greater detail below.

- Electrico: the manufacturing planning system was too inflexible to support the FPp application without the support of finished cable buffer stocks. There were two major shortfalls in the planning system: a planning time of two days and a MRP regeneration frequency of once per week. This added a potential six days' waiting time before new orders could be processed. In effect the planning leadtime for FPp orders had not been reduced at all compared to that for orders subject to MTO. Instead Electrico's and their customer's planning systems were synchronised but this did not take into account the customer's high level of deviation from the manufacturing plan.

- Motorco: all modifications involved removal of parts, resulting in increased manufacturing time and costs. Almost half the motors modified required invasive modifications involving changes to the magnet body components. This commonly involved a motor strip down which could take up to 3 working days. The CODP would have better been located further upstream in the manufacturing process. A better location would have been at the balanced armature stage, since the armature 
was not subject to modifications. The magnet body assembly and final motor assembly would then be postponed (conducted to customer orders). With a manufacturing lead-time of just 8 working days it would still have been possible to provide modified standard motors on a 3 to 4 week lead-time. While this approach would not have reduced the number of generic SKUs, it would have reduced their value and increased their flexibility. This would have allowed generic ex-stock availability to be improved while reducing stock value.

- Controlco: it was envisaged that the number of plastic keytip colour configurations on the EPP keypads would be limited to about five, and that only stocks of these generic keypad variants would be maintained. Only laser marking of the legend on the keytips would be performed to customer order: no component stocks would be required, and the keypads could be supplied on short lead-times. However, demand for EPP keypads was not as the customer forecasted. The EPP keypad was demanded in eighteen - rather than five - different keytip colour configurations. This meant that Controlco had to locate the CODP further upstream than planned, and stock generic keypads (which weren't colour configured) together with the many variants of keytips. The implications for processing were that - rather than just laser marking - gluing and populating of the keytips onto the keypads were also performed to customer order. Given the low value adding time (4.5 minutes) to total manufacturing lead-time of the unconfigured keypads it would have been possible for Controlco to assemble the keypads entirely to order and only manufacture the keytips to stock. But Controlco would then have lost the buffer stock of unconfigured keypads which protected the generic keypad assembly process from the high demand variability. 
Generic keypad assembly - as well as gluing and populating - would then have required excess capacity.

\section{Analysing the Results against our Propositions}

We listed our six propositions above in section 2 and summarised them in table 1. Here, we analyse our results against those six propositions.

\subsection{Demand profile}

Results from the three case studies against propositions P1 and P2 are listed in table 5. They were tested and supported by all three case studies - with the exception of P1, which was challenged by findings from Electrico.

Table 5: Cross-case comparison of the demand profile measures related to propositions $\mathbf{P} 1$ and $\mathbf{P} 2$.

Demand mix, demand variability and volume demand: In the Electrico study both demand mix and demand variability were lower - and volume demand was higher for cables made under FPp compared with those made under MTS. These unexpected findings can be attributed to the FPp application being artificially restricted to one customer and further restricted to high volume cables (as described in section 3.2). Therefore these findings do not fundamentally challenge our propositions.

At Motorco and Controlco, demand mix and demand variability were higher - and volume demand was lower - for products made under FPp compared with those made under MTS. At Motorco, FPp motors were demanded in four times as many variants as MTS motors, so demand variability at finished motor level was higher and volume demand was lower. Similarly at Controlco the EPP keypads subject to FPp were demanded in seven times as many variants as MTS pushbutton bodies. 
Volume demand at generic level: As predicted by $\mathrm{P} 2$, generic products selected for manufacture under FPp exhibited higher volume demand than those which were MTO in all three cases. This was attributable to variations in the MTO generic product specification that did not exist in the FPp generic product. At Electrico, 2 generic cables in the MTO UoA compared to 1 in the FPp UoA. At Motorco, there were 155 generic motors in the ETO UoA compared to 24 generic motors in the FPp UoA. At Controlco, there were 6 generic keypads in the MTO UoA compared to 3 in the FPp UoA.

\subsection{Customer Service and Demand Amplification}

Our research questions and respective propositions relating to customer service measures (ex-stock availability, order lead-time and delivery reliability) and demand amplification are encompassed in propositions 3 and 4. Results from the three case studies are summarised in table 6. Proposition P3 was not tested by either the Electrico or Motorco case studies. However it was tested at Controlco and our findings supported P3. P4 was tested and supported by all three case studies with the exception of the delivery reliability findings from at Electrico, which challenged P4.

Ex-stock Availability: P3 remained untested at Electrico due to a lack of appropriate data. This was also partially true of the Motorco study. However the principal reason for proposition P3 not being tested at Motorco was that P3 pre-supposed that orders subject to FPp and MTS did not pull from the same product stocks as they did at Motorco.

Table 6: Cross-case comparison of customer service and demand amplification propositions $\mathbf{P 3}$ and $\mathbf{P 4}$. 
At Controlco ex-stock availability we measured the proportion of enquiries and orders for which the correct stock item was available. For EPP keypads the combination of no stock outs (in the generic keypads), no enquiries (only firm orders) and a high delivery performance ( $98 \%$ on time in full) indicated that ex-stock availability was above $98 \%$. Stock outs were recorded for three of the MTS pushbutton bodies and this alone reduced delivery reliability to $94 \%$ on time in full. Further unlike the EPP keypads pushbutton bodies were subject to enquiries for which the ex-stock availability was not recorded. Therefore it was concluded that ex-stock availability for pushbutton bodies was at best $94 \%$.

At Controlco the high ex-stock availability achieved by FPp compared with MTS was attributable to the reduced number of generic product SKUs and the accompanying reduction in demand variability.

Delivery Reliability: Delivery reliability at Electrico achieved by FPp was lower than that achieved by MTO - only $51 \%$ of FPp orders compared to $76 \%$ of MTO orders were available OTIF. This challenged proposition P4. Reduced delivery reliability under FPp was largely accounted for by $20 \%$ of orders that were only partially available on the due date. Two possible explanations were advanced for poor delivery reliability under FPp: a lack of postponed sheathing capacity, and insufficient generic cable stock. The underlying cause of these factors was the unusual circumstances of this case. The major customer of cables subject to FPp was allowed to call off finished cables rather than have them delivered upon completion. Finished cable 
stock provided a buffer against poor delivery reliability. Electrico would otherwise have been forced to address poor delivery reliability.

Delivery reliability at both Motorco and Controlco was higher for products subject to FPp than the MTO products. At Motorco, improvement in delivery reliability provided by FPp was unexpectedly modest. There were three possible explanations:

- quoted lead-times for the FPp motors often did not take into account availability of modification parts.

- limited resources in the Service and Repair section, where two thirds of the modifications took place.

- low generic motor stocks provided only $63 \%$ ex-stock availability .

Order Lead-time: In all three cases, order lead-times achieved under FPp were substantially less than that achieved under MTO, supporting proposition P4. This was in part because a significant proportion of manufacturing was conducted speculatively to stock rather than to order. Other factors contributed to the reduction in order leadtime achieved by FPp.

- Electrico: the order lead-time was just under half of that achieved by MTO. This was partially due to synchronisation of the weekly manufacturing planning process at Electrico and customer.

- Motorco: the order lead-time was less than a quarter of that achieved under ETO. This was in part due to dramatic reductions in engineering and bought-in parts lead-times. 
- Controlco: the order lead-time for EPP keypads (FPp) was one fifth of that achieved for MA keypads (MTO). This was double the responsiveness requested by customer, and was in part due to a more responsive approach to order processing and manufacturing planning.

Demand amplification: In all three cases, demand amplification was not found for MTO or ETO, but was detected for FPp - supporting proposition P4. Demand amplification was always detected in manufacture of generic product to stock, but not at the FPp stage. Exceptionally, demand amplification at Electrico was detected at the order-driven sheathing process - albeit to a lesser extent. This was attributable to the long weekly planning cycle, which created the opportunity to batch similar customer orders together.

\subsection{Product Design}

Results from the three case studies in relation to proposition P5 are summarised in table 7. P5 was fully tested and fundamentally challenged by the product modularity findings from all three studies.

Table 7: Cross-case comparison of product modularity and standardization measures ( proposition P5).

Product Standardization: In all three cases, products subject to FPp demonstrated a higher level of standardization than MTO or ETO. At Electrico and Motorco this was both in terms of the proportion of common components and the degree of commonality index. The commonality index exhibited under FPp was almost three times higher than that for MTO, and it was higher at every level in the BOM. At lower BOM levels, this was due to FPp being applied to fewer generic products than 
MTO or ETO. At higher BOM levels relating to postponed processes, high commonality occurred for different reasons. At Electrico it was due to limitation of FPp to one customer which enabled standardization of packaging components and limited the range of sheathing compounds. At Motorco it was simply due to customer requirement for less variety in peripheral components of motors subject to FPp.

At Controlco a much greater proportion of EPP keypad components was common to all variants than MA keypad components (48\% compared with 3\%) and this was due to a single generic body design serving the full range of EPP keypads. Unexpectedly, EPP and MA keypads exhibited a very similar degree of commonality index overall $14 \%$ compared with $15 \%$ respectively. However the source of commonality was quite different - commonality in the generic keypad was higher for EPP keypads whereas commonality in the keytips (the configuring components) was higher for MA keypads.

Product Modularity: In all three cases the degree of modularity exhibited by products subject to FPp was the same as that exhibited by products subject to MTO/ETO. The distinction in modularity was between customising components (supplied to the postponed process) and components in the generic product. Customising components required by all three products subject to FPp were highly modular, with the exception of some of the components required for Motorco motor modifications. Components in the generic products exhibited a lower degree of modularity (with the exception of the cables at Electrico which were highly modular throughout). 
Degree of modularity demonstrated by all products was an incidental characteristic rather than the result of a deliberate product design effort. This even applied to the EPP keypad, which was the only product specifically designed for FPp.

\subsection{Excess Capacity and Throughput Efficiency}

Results for proposition P6 are summarised in table 8. P6 was fully tested in the Motorco and Controlco case studies, but only in part in the Electrico case - where it was challenged by the excess capacity findings. P6 was fully supported at Motorco but was challenged by throughput efficiency findings at Controlco.

Table 8: Cross-case comparison of the excess capacity and throughput efficiency measures (proposition P6).

Excess Capacity: In both Motorco and Controlco cases, excess capacity at the postponed processes (as indicated by low utilisation and high design capacity levels) was higher than at preceding stock-driven processes - supporting P6. At Motorco the final assembly cell (where a third of the postponed motor modifications took place) consistently demonstrated lower utilisation levels than any of the preceding cells. At Controlco, average capacity utilisation was significantly lower for the EPP keypad configuration cell than the stock-driven EPP assembly cell.

At Electrico, the postponed sheathing process consistently exhibited the least excess capacity compared to the preceding processes - challenging P6. This was attributable to the provision of less capacity at the postponed process, due to the unusual circumstances at Electrico. Lack of sheathing capacity contributed to poor delivery reliability achieved by FPp (which itself challenged P4) and would have been addressed had it not been for the buffer of finished cable stocks (see above). 
Throughput Efficiency: P6 was not tested with respect to throughput efficiency at Electrico because it was not possible to take this measure for the postponed process.

At Controlco, throughput efficiency was higher for the stock driven, generic EPP keypad assembly than it was for the postponed configuration - $27 \%$ compared to 11\%. This challenged P6, although manufacturing lead-times for the postponed configuration were shorter than for the generic keypad assembly process - 3 compared to 17.5 working days respectively. There were two explanations for the low throughput efficiency we found at the postponed configuration process:

- high generic keypad stock targets - equivalent to 4 weeks cover - encouraged large generic keypad stock replenishment orders. These were much greater than the size of the customer orders for configured keypads - 520 compared with 45 respectively.

- at the postponed configuration process queuing caused by capacity restrictions extended the manufacturing lead-time by over $500 \%$.

These problems were due to flaws in the FPp application at Controlco. High generic stock levels ensured that the stock driven generic processing was far from the 'lean' ideal and the postponed keypad configuration process demonstrated a lack of responsiveness. However, greater responsiveness was not required as FPp already provided double the responsiveness requested by customer.

Findings from Motorco supported P6. Throughput efficiency for postponed modifications was, on average, double that achieved by stock-driven manufacture of generic stock motors (21\% compared to $10 \%)$. However, as at Controlco, throughput efficiency measured for the postponed process was highly variable from order to order 
(four times that for generic motor manufacture). Variability in throughput efficiency was mainly driven by the variety of modifications - which required anything from 10 minutes to 26 working hours.

At both Controlco and Motorco, the most striking difference between generic product manufacture and the postponed processes was not throughput efficiencies but manufacturing lead-times. Postponed processes were clearly more responsive with a manufacturing lead-time equivalent to only $18 \%$ of the generic product manufacturing lead-times.

\subsection{Production Variety}

At Electrico and Controlco the number of SKUs at the CODP was greater than the number of finished product variants demanded - eight SKUs compared to five finished cables at Electrico and 179 SKUs compared to 72 finished keypads at Controlco (figure 1). This is contrary to the original conceptual model of FPp which predicted the number of SKUs at the CODP to be substantially less than the number of finished items.

\section{Figure 1: Production variety funnels for Controlco's products where EPP}

\section{keypads are subject to FPp}

In both cases this situation was not a feature of the duration of the study but a feature of the product. At Electrico even if FPp had not been restricted to one customer this situation would have persisted because for every new finished cable variant a new sheathing polymer was likely to be required. At Controlco, although the theoretical potential number of finished EPP keypads was much greater than 72, this product was 
supplied exclusively to one customer and therefore the actual number of finished items was unlikely to change significantly.

At Motorco, 24 generic motors were stocked and 51 different components were supplied into the postponed process, but the number of SKUs at the CODP was less than the 56 finished motor variants demanded. This was attributable to the fact that many of the components were purchased (or made) to customer order. This was possible because there was a sufficient order lead-time during which to do this and necessary because the finished motors were truly customised therefore the customising components were not predictable.

\section{Frameworks for Application of Form Postponement}

None of the FPp applications was ideal, and this created anomalies in the findings. The FPp application in the initial study at Electrico was flawed to the extent that after nine months it could no longer be defined as FPp. At Motorco the FPp application was sustainable, but the customising process involved the removal of previously added components. Finally the FPp application at Controlco most closely resembled an 'ideal' application - but was not the planned ideal application!

Anomalies in our findings resulted in a number of hypotheses being challenged - we did not find predicted results, but for predictable reasons. Our propositions were based on ideal FPp applications, so some of them were challenged when tested in less than ideal applications. When the complete picture was built up of how FPp was applied in each case, challenges to our propositions were understandable and predictable. Yin (2003) refers to this as 'theoretical replication'. 'Literal replication' was sought where results were predicted to be similar for each case. 
Anomalies in the findings revealed important links between poor delivery reliability and lack of excess capacity at the postponed process, and suggested that in practice throughput efficiency is not a crucial measure. Taking these into account, our propositions remain largely unscathed - except for that regarding product modularity, which was fundamentally challenged by each study.

This section describes the two frameworks, based on the propositions and the original conceptual model, that were developed from these studies. We also summarise obstacles to applying FPp

\subsection{Inventory Management Decision Framework}

The inventory management decision framework shown in table 9 shows when FPp is a viable alternative to either MTS or MTO on the basis of demand profile (at generic and end item level), customer service and demand amplification.

\section{Table 9: Inventory Management Decision Framework for Unicentric FPp.}

Opportunities for applying FPp to MTO products depends on the demand profile at generic level. Generic product variants which are subject to low demand variability and high volume demand (as in Electrico and Controlco cases). Otherwise, it may be possible to re-design the product through process and component standardization to create a narrow range of generic products demanded in sufficient volumes for application of FPp.

A key incentive for applying FPp to MTO products is the possibility of improving delivery reliability and significantly reducing order lead-times. A more responsive product supply may be needed to improve competitiveness. Introduction of FPp will 
impact suppliers, who should be able to manage the levels of demand amplification likely to be introduced.

Opportunities for applying FPp to MTS products depend on the demand profile for the finished products, and are indicated by inaccurate sales forecasting, stock outs and excessive stocks. These products exhibit high product mix (or potentially high product mix), high demand variability and low volume demand at end item level. Redesign of MTS products may be necessary to establish a narrow range of generic products demanded in sufficient volumes to enable application of FPp.

Incentives for applying FPp to MTS products include the possibility of improving exstock availability. Stock-outs may be critical and not tolerated by customer, as at Controlco. Further risks are associated with inflexible finished stock levels, such as obsolescence. Demand amplification should be reduced on components supplied to the postponed process, enabling a more sufficient supply. But postponed processes must not extend the order lead-time beyond that acceptable to customer.

Our framework has some limitations:

- $\quad t t$ considers only 'unicentric' FPp - where the postponed processes take place in the same location as generic processes. Therefore distribution is not considered.

- demand profiles at generic level can be changed either by relocating the CODP or re-designing product and processes.

- product value is not considered. If this is particularly high it will tend to discourage stock-driven processing and if it is low it will tend to have the opposite effect. 


\subsection{Framework for the Application of Form Postponement}

Our main contribution is the practical implications of applying FPp within a manufacturing facility. We propose a framework which provides practical guidance on how FPp can be applied - in terms of product design, inventory management, manufacturing planning and scheduling operations.

We have revised our original conceptual model of FPp (Skipworth and Harrison, 2004) to take account our empirical findings. Our new framework applies to 'unicentric' FPp applications, where the product exhibits component swapping modularity. Our framework illustrates major operational implications of applying FPp which are described in this section.

Where products exhibit component swapping modularity, the number of SKUs at the CODP could be greater than the number of finished product variants, contrary to our original conceptual model of FPp. However our studies have shown that there are still benefits to be gained from FPp over MTS. The PVF in our new framework shown in figure 2 illustrates that, although the number of generic products at the CODP is always small compared to the number of finished product items, the total number of components supplied into the postponed process may not be. This applied to all three studies, and at Electrico and Controlco the total number of SKUs at the CODP was greater than the number of finished product items.

The key benefit of FPp is that it improves the flexibility of stocks by keeping them in generic form at the CODP, rather than committed as in MTS. This enables safety stocks to be reduced whilst offering the full range of finished items. 


\section{Figure 2: Framework for the application of FPp.}

Locating the CODP: The CODP should be located at a 'neck' in the Production Variety Funnel (figure 2). This is typically at the generic product stage such that:

- no previously added value should be removed during the postponed process. There must be no removal of components or rework.

- postponed value added processing time must be short compared to the total value adding process time required to manufacture the product

- the number of generic product variants must be kept to a minimum. Each variant should be subject to high volume demand and low volume demand variability $(\mathrm{CV})$ relative to the end items.

Our findings should be contrasted with some of the rules for locating the CODP that have appeared in the literature. An example is that 'postponement is about delaying the activities (as to the form and/or place of goods) until the latest possible point in time' (Yang et al, 2004a). This is based on the view that short order lead times are paramount, and ignores the trade-off between order lead time, number of SKUs, demand variability and safety stocks required. For a high variety product, it is problematic to place the decoupling point to allow immediate delivery without maintaining high level stocks: the advantages of postponement would be correspondingly reduced.

Product Design: A high proportion of the product should be standardised whilst ensuring that the required customisation levels can still be achieved. Standardization that involves material redundancy should be avoided where possible. Remaining differentiations should be postponed. 
Ideally components supplied to the postponed process should be highly modular, so that:

- a one-to-one correspondence exists between each functional element and physical component (or module)

- interactions between components are critical to functioning of the system. Therefore it should be possible to combine components in many ways to support a wide product range.

Inventory Management: we identified five conditions for order processing and inventory control:

- EDI is a rapid and reliable way of transmitting customer orders, particularly when electronic data such as bar codes are required. However EDI is only practical when the customer places orders at regular intervals. Further the improved responsiveness offered by EDI transmission of orders can best be realised if orders are processed upon arrival. If these conditions do not apply and orders can be placed anytime then some type of broadcasting mechanism must be deployed for the orders upon receipt. This could involve kanbans faxed ('faxban') by the customer.

- Generic product stock level should provide forward cover that takes into account volume demand variability (measured by CV) at this level.

- If demand for the generic products and components is sufficiently stable they can be supplied to the postponed process under Kanban control. This was the case for the keytips at Controlco.

- Components at the postponed process must be available on a short enough lead-time. In practice this implies that components are available ex-stock. However this is not possible when a product is truly customised since the 
customising components cannot be predefined (as at Motorco). In this case it must be ensured that suppliers can deliver to order on a suficiently short leadtime. This is often not possible and leads to FPp being limited to a set of predefined end items (as at Electrico and Controlco).

- Generally standard quoted lead-times which apply to all orders are only possible where FPp is applied to a predefined set of end items (as at Electrico and Controlco). Where products are truly customised quoted lead-times must depend on component availability and are therefore variable, as the Motorco case demonstrated.

Manufacturing Planning and Control: we identified four conditions for manufacturing planning systems and capacity management:

- The order processing and manufacturing planning systems for the postponed process must be highly responsive. This often requires a real time planning system - a fixed period MRP system for the postponed processing does not support FPp applications for two reasons. Firstly the order processing time from order logging to availability for manufacture tends not to be short enough, in part due to the regeneration frequency of fixed period MRP systems. Secondly fixed period MRP systems restrict due dates to typically weekly time buckets. Only in the Electrico case was a fixed period MRP system used for the finished product and the failure of FPp, in this case, was mainly attributable to this.

- Where the postponed process is more complex and especially where the product is truly customised (Motorco) an MRP system may be desirable. Configurable BOMs will be required so that any potential finished product BOM can be quickly established for an order.

- Substantial excess capacity should be provided at the postponed process to enable it to remain responsive when subjected to high demand variability in terms of product mix, and to a lesser extent volume (i.e. demand variability at 
generic level). Delivery reliability can suffer when sufficient excess capacity is not provided (as at Electrico and Motorco).

- Throughput efficiency is not the crucial issue at the postponed process - it tends to be highly variable. Rather it is important to ensure that manufacturing lead-times are sufficiently short to meet customer required order lead-times. This may imply limitations to the quantities or customisations that can be delivered within standard quoted lead-times for FPp.

\subsection{Obstacles to the application of FPp}

Product design: The aim is to standardize the product to provide few generic products and to modularise customizing components. This is dependant on the demand profile as well as on product characteristics. At Controlco the demand profile made it impossible to standardize the colour configured keypad. But by moving the CODP upstream, a more standardized generic product was identified. At Motorco the generic motor was demanded in 24 variants and even moving the CODP upstream would not reduce this number.

Manufacturing Planning and Control: mindsets associated with MTO and MTS are inhibitors to FPp, an aspect of the lack of structural and cultural fit referred to by Yang et al (2004b). MTO and MTS tend not to require either manufacturing planning or manufacturing processes to be responsive compared with FPp.

All three cases demonstrated that legacy order processing and manufacturing planning systems are inhibitors to FPp applications. At both Electrico and Controlco, the fixed period MRP systems were insufficiently responsive to process customer orders for FPp products. At Motorco, the MRP system was responsive enough, but the BOMs lacked flexibility. 
Postponed Process Capacity: when this is insufficient to maintain the required responsiveness in terms of short, reliable lead-times it presents an obstacle to the application of FPp. At Electrico, lack of buffer capacity at the postponed process contributed to reduced delivery reliability provided by FPp compared to MTO. At Motorco, lack of resource and focus in the department performing postponed modifications was a strong contributing factor to poor delivery performance.

\section{Conclusions}

Our research shows the conditions under which FPp is preferred to MTO or MTS.

- When there is a need for greater responsiveness, in terms of shorter order leadtimes, than MTO can deliver.

- When sales forecasts for MTS finished products are very inaccurate, and repositioning the stock further upstream where it is more flexible reduces inventory management risks.

Based on the evidence from our three case studies, the ideal application of FPp remains elusive. This is related to the major operational challenges involved in its application. This begs the question 'would efforts be better invested in improving the existing MTO and MTS approaches?' We consider each case in turn.

- Motorco: finished motor specifications subject to FPp were not predefined. Instead the motors were truly customised. Therefore MTS was not an option because it was not possible to predict and stock the full array of finished motors. MTO on the other hand would not have enabled the motors to be delivered within the 3 to 4 weeks lead-time expected by UK customers (for modified standard motors) - the best achievable by MTO was 6 to 10 weeks depending on motor size. 
So if Motorco wanted to sell modified standard motors to UK customers, the only option was FPp.

- Controlco: FPp was applied to a set of predefined finished product variants, so MTS was an option. However this would have required very high finished stock levels to ensure stock availability in the face of such high demand variability. Moreover the customer did not need immediate availability and was satisfied with a 5 working day lead-time. MTO on the other hand was not a possibility because keytip manufacture involved numerous distinct processes, and a high minimum batch quantity, resulting in a long manufacturing lead-time. Applying FPp by making at least the keytips to a speculative stock was the only approach that minimised inventory whilst enabling the customer service need to be met.

- Electrico: if the difficulties with the manufacturing planning and scheduling system had been overcome, substantial benefits could have been realised. Design of the majority of Electrico's cables was ideal for FPp and presented no obstacles. The MTO lead-time of 3 weeks could have been cut to 3 days, enabling cable supply to be matched with customer demand and all finished stocks eliminated. This would have provided Electrico with the ability to provide exceptionally responsive service without the need for high value finished goods stock.

Our study shows that even flawed FPp applications offer significant benefits, and are worth undertaking. So is it worth going the extra mile and applying FPp in an ideal way? In the Motorco case, improvements in the FPp application would have delivered reductions in manufacturing costs and improvements in delivery reliability without reducing responsiveness or increasing inventory costs. At Controlco, FPp 
was already providing double the responsiveness requested by the customer and delivery reliability was very high: there were no further advantages to be gained through improvements in customer service.

Improvements in a FPp application are subject to the same criteria as other operations improvements - they are worth implementing if they deliver either reductions in manufacturing costs or improvements in customer service that will provide competitive advantage.

Acknowledgement

We acknowledge the financial support provided by the Engineering and Physical Sciences Research Council (EPSRC) in conducting this project. 


\section{References}

BICHENO, J., 1998, The Lean Toolbox (Buckingham, England: Picsie Books)

COLLIER, D.A., 1981, The Measure and Operating Benefits of Component Part Commonality. Decision Science, 12, 85-96

COLLIER, D.A., 1982, Aggregate Safety Stock Levels and Component Part Commonality. Management Science, 28, 1296-1303.

MIKKOLA J. and SKJФTT-LARSEN, T., 2004, Supply-Chain Integration: Implications for Mass Customisation, Modularisation and Postponement strategies, Production Planning and Control, Vol 15 No 4, June, pp 352-361

SKIPWORTH, H. and HARRISON, A., 2004, Implications of Form Postponement to Manufacturing: a case study, International Journal of Production Research, 42 (10), pp. 2063

SKIPWORTH, H. and HARRISON, A., 2006, Implications of Form Postponement to Manufacturing a Customized Product, International Journal of Production Research, 44 (8), pp. 1627-1652.

ULRICH, K.T., 1994, Fundamentals of Product Modularity. In S. Dasu (ed), Management of Design: Engineering and Management Perspectives (Boston: Kluwer Academic Publishers), chapter 12, pp. 219-229

VAN HOEK, R. I., 2001, The Rediscovery of Postponement a Literature Review and Directions for research, Journal of Operations Management, Vol 19, pp 161-184

YANG, B. and BURNS, N., 2003, Implications of Postponement for the Supply Chain, International Journal of Production Research, 41, 2075-2090.

YANG, B., BURNS, N., and BACKHOUSE, C., 2004a, Management of Uncertainty through Postponement, International Journal of Production Research, Vol 42 No 6, 1049-1064.

YANG, B., BURNS, N. and BACKHOUSE, C., 2004b, Postponement: a Review and an Integrated Framework, International Journal of Operations and Production Management, 41, 2075-2090.

YIN, R., 2003, Case Study Research - Design and Methods, $3^{\text {rd }}$ ed. (Sage) 
Table 1: Theoretical framework illustrating the propositions

\begin{tabular}{|c|c|c|c|c|c|c|}
\hline \multicolumn{3}{|c|}{ Characteristic } & \multirow{2}{*}{$\begin{array}{l}\text { ETO } \\
\text { or } \\
\text { MTO } \\
\text { High } \\
\end{array}$} & \multirow{2}{*}{$\begin{array}{l}\text { FPp } \\
\text { High } \\
\end{array}$} & \multirow{2}{*}{$\begin{array}{c}\text { MTS } \\
\text { Low } \\
\end{array}$} & \multirow{3}{*}{$\begin{array}{c}\text { Proposition } \\
\text { P1 }\end{array}$} \\
\hline \multirow{4}{*}{$\begin{array}{l}\text { Product } \\
\text { Demand } \\
\text { Profile }\end{array}$} & \multirow{3}{*}{$\begin{array}{l}\text { End } \\
\text { item } \\
\text { level }\end{array}$} & Demand mix & & & & \\
\hline & & Demand variability & High & High & Low & \\
\hline & & Volume demand & Low & Low & High & \\
\hline & $\begin{array}{l}\text { Generi } \\
\text { c level }\end{array}$ & Volume demand & Low & High & High & $\mathbf{P 2}$ \\
\hline \multirow{3}{*}{\multicolumn{2}{|c|}{ Customer Service }} & $\begin{array}{l}\text { Ex-stock } \\
\text { availability }\end{array}$ & $\mathrm{n} / \mathrm{a}$ & High & $\begin{array}{l}\text { Mediu } \\
\text { m }\end{array}$ & $\mathbf{P 3}$ \\
\hline & & Order lead-time & Long & Short & Short & \multirow{3}{*}{ P4 } \\
\hline & & $\begin{array}{l}\text { Delivery } \\
\text { Reliability }\end{array}$ & $\begin{array}{l}\text { Mediu } \\
\text { m }\end{array}$ & High & $\mathrm{n} / \mathrm{a}$ & \\
\hline \multicolumn{3}{|c|}{ Demand amplification } & None & Low & High & \\
\hline \multirow{2}{*}{\multicolumn{2}{|c|}{ Product Design }} & $\begin{array}{l}\text { Product } \\
\text { Standardization }\end{array}$ & Low & $\begin{array}{l}\text { Mediu } \\
\text { m }\end{array}$ & High & \multirow[t]{2}{*}{ P5 } \\
\hline & & Product modularity & Low & High & Low & \\
\hline \multicolumn{3}{|c|}{ Excess Capacity } & High & $\begin{array}{l}\text { Mediu } \\
\text { m }\end{array}$ & Low & \multirow{2}{*}{ P6 } \\
\hline \multicolumn{3}{|c|}{ Throughput efficiency } & High & $\begin{array}{l}\text { Mediu } \\
\text { m }\end{array}$ & Low & \\
\hline
\end{tabular}


Table 2: Comparison of the UoAs used in the three case studies

\begin{tabular}{|l|l|l|l||}
\hline $\begin{array}{l}\text { Units of } \\
\text { Analysis }\end{array}$ & Electrico & Motorco & Controlco \\
\hline \hline ETO/MTO & 3183 Y1.00 cable & Contract LDC motors & MA Keypads \\
\hline FPp & $\begin{array}{l}3183 \text { Y } 1.00 \text { cable } \\
\text { (1 generic cable) }\end{array}$ & $\begin{array}{l}\text { Modified } \\
\text { standard LDC motors } \\
(24 \text { generic motors })\end{array}$ & $\begin{array}{l}\text { EPP Keypads } \\
\text { (3 generic keypads) }\end{array}$ \\
\hline MTS & 3183 Y1.00 cable & $\begin{array}{l}\text { UK standard LDC } \\
\text { motors }\end{array}$ & PB bodies \\
\hline Period of Study & 5 months & 12 months & 4 months \\
\hline
\end{tabular}


Table 3: Cross-case comparison of contextual data relating to the FPp applications

\begin{tabular}{|c|c|c|c|}
\hline & Electrico & Motorco & Controlco \\
\hline $\begin{array}{l}\text { Product } \\
\text { Description }\end{array}$ & $\begin{array}{l}\text { Low voltage } \\
\text { flexible energy } \\
\text { cables }\end{array}$ & $\begin{array}{l}\text { Large Direct } \\
\text { Current (LDC) } \\
\text { motors }\end{array}$ & $\begin{array}{l}\text { Encrypted Pin Pad } \\
\text { (EPP) }\end{array}$ \\
\hline $\begin{array}{l}\text { Volume - } \\
\text { variety }\end{array}$ & $\begin{array}{l}\text { Low variety, high } \\
\text { volume }\end{array}$ & $\begin{array}{c}\text { High variety, low } \\
\text { volume }\end{array}$ & $\begin{array}{l}\text { High variety, high } \\
\text { volume }\end{array}$ \\
\hline $\begin{array}{l}\text { Distinct } \\
\text { Components }\end{array}$ & 18 & 160 & 30 \\
\hline $\begin{array}{l}\text { Manufacturing } \\
\text { Processes }\end{array}$ & $\begin{array}{l}\text { Equipment driven } \\
\text { semi-continuous }\end{array}$ & $\begin{array}{c}\text { Labour driven } \\
\text { assembly and other } \\
\text { processes }\end{array}$ & $\begin{array}{l}\text { Labour driven simple } \\
\text { assembly }\end{array}$ \\
\hline $\begin{array}{l}\text { Typical order } \\
\text { quantity }\end{array}$ & $60 \mathrm{~km}$ & 1 motor & 45 keypads \\
\hline $\begin{array}{l}\text { Value added } \\
\text { processing time }\end{array}$ & $\begin{array}{l}36 \text { minutes per } \mathrm{km} \\
36 \text { hours per } 60 \mathrm{~km}\end{array}$ & 37 hours per motor & $\begin{array}{l}9 \text { minutes per keypad } \\
7 \text { hours per } 45 \text { keypads }\end{array}$ \\
\hline $\begin{array}{l}\text { Reasons for } \\
\text { application }\end{array}$ & $\begin{array}{c}\text { Improve } \\
\text { responsiveness } \\
\text { offered by MTO }\end{array}$ & $\begin{array}{l}\text { Improve } \\
\text { responsiveness } \\
\text { offered by ETO }\end{array}$ & $\begin{array}{l}\text { Improve } \\
\text { responsiveness offered } \\
\text { by MTO and reduce } \\
\text { component inventories }\end{array}$ \\
\hline
\end{tabular}


Table 4: Cross-case comparison of the 'change content' data for the FPp applications.

\begin{tabular}{|c|c|c|c|}
\hline FPp application & Electrico & Motorco & Controlco \\
\hline \multicolumn{4}{|c|}{ Selection of customers and products } \\
\hline Customers & $\begin{array}{l}\text { Biggest customer } \\
\text { only }\end{array}$ & Any & $\begin{array}{l}\text { Biggest customer } \\
\text { only }\end{array}$ \\
\hline Products & $\begin{array}{l}\text { High volume } \\
\text { finished cables }\end{array}$ & $\begin{array}{l}30 \text { UK standard } \\
\text { motors }\end{array}$ & $\begin{array}{l}\text { All EPP keypads } \\
\text { (predefined end } \\
\text { items) }\end{array}$ \\
\hline \multicolumn{4}{|c|}{ Product and Processes } \\
\hline $\begin{array}{l}\text { Stocked generic } \\
\text { product }\end{array}$ & 5 Laid-up cables & $\begin{array}{l}30 \text { UK standard } \\
\text { motors }\end{array}$ & $\begin{array}{l}3 \text { Unconfigured } \\
\text { keypads }\end{array}$ \\
\hline $\begin{array}{l}\text { Postponed } \\
\text { processes }\end{array}$ & Sheath extrusion & Modifications & $\begin{array}{l}\text { Populating keypad } \\
\text { with keytips }\end{array}$ \\
\hline \multicolumn{4}{|c|}{ Inventory Management } \\
\hline $\begin{array}{l}\text { Standard quoted } \\
\text { lead-time }\end{array}$ & $6-10$ days & $1-4$ weeks & 1 week \\
\hline $\begin{array}{l}\text { Customer orders } \\
\text { entered onto SOB }\end{array}$ & Every Tuesday & Any time & Daily at 9:00am \\
\hline $\begin{array}{l}\text { Component supply } \\
\text { into the postponed } \\
\text { process }\end{array}$ & $\begin{array}{l}\text { Supplier } \\
\text { consignment stocks }\end{array}$ & $\begin{array}{l}\text { Made in-house, } \\
\text { stocked, purchased } \\
\text { to order }\end{array}$ & $\begin{array}{l}\text { Made in-house to } \\
\text { Kanbans }\end{array}$ \\
\hline \multicolumn{4}{|c|}{ Manufacturing Planning } \\
\hline Customer orders & Processed by MRP & By-passed MRP & By-passed MRP \\
\hline $\begin{array}{l}\text { MRP system driven } \\
\text { by fixed period } \\
\text { MPS used for.... }\end{array}$ & All production & $\begin{array}{lr}\text { MTO, } & \text { MTS } \\
\text { (including generic } & \text { gotors for } \\
\text { FPp) }\end{array}$ & $\begin{array}{l}\text { MTS and generic } \\
\text { keypads for FPp }\end{array}$ \\
\hline $\begin{array}{l}\text { Release } \\
\text { manufacturing } \\
\text { orders to shopfloor }\end{array}$ & Every Friday & Anytime & Daily at 10:30am \\
\hline $\begin{array}{l}\text { Order Processing } \\
\text { and } \\
\text { Manufacturing } \\
\text { Planning Lead- } \\
\text { time }\end{array}$ & $\begin{array}{l}3 \text { days (excluding } \\
\text { possible waiting } \\
\text { time of } 6 \text { days) }\end{array}$ & 1 - 3 days & 1.5 hours \\
\hline
\end{tabular}


Table 5: Cross-case comparison of the demand profile measures related to propositions $\mathbf{P 1}$ and $\mathbf{P 2}$.

\begin{tabular}{|c|c|c|c|c|}
\hline \multirow{2}{*}{\multicolumn{2}{|c|}{$\begin{array}{l}\text { Propositions and } \\
\text { Measures }\end{array}$}} & \multicolumn{3}{|c|}{ Supported } \\
\hline & & \multirow{2}{*}{$\begin{array}{c}\text { Electrico } \\
\text { No }\end{array}$} & \multirow{2}{*}{$\begin{array}{c}\text { Motorco } \\
\text { Yes }\end{array}$} & \multirow{2}{*}{$\frac{\text { Controlco }}{\text { Yes }}$} \\
\hline \multirow{3}{*}{$\begin{array}{l}\text { P1: } \\
\text { FPp } \\
\text { v } \\
\text { MTS }\end{array}$} & Demand mix & & & \\
\hline & $\begin{array}{l}\text { Demand } \\
\text { variability }\end{array}$ & No & Yes & Yes \\
\hline & $\begin{array}{l}\text { Volume } \\
\text { demand }\end{array}$ & No & Yes & Yes \\
\hline $\begin{array}{l}\text { P2: } \\
\text { FPp } \\
\text { v } \\
\text { MTO }\end{array}$ & $\begin{array}{l}\text { Volume } \\
\text { demand } \\
\text { (generic } \\
\text { level) }\end{array}$ & Yes & Yes & Yes \\
\hline
\end{tabular}


Table 6: Cross-case comparison of the customer service and demand amplification propositions $\mathrm{P} 3$ and $\mathrm{P} 4$.

\begin{tabular}{|c|c|c|c|c|}
\hline \multirow{2}{*}{\multicolumn{2}{|c|}{$\begin{array}{l}\text { Propositions \& } \\
\text { Measures }\end{array}$}} & \multicolumn{3}{|l|}{ Supported } \\
\hline & & Electrico & \multirow{2}{*}{$\begin{array}{l}\text { Motorco } \\
\text { Not tested }\end{array}$} & \multirow{2}{*}{\begin{tabular}{|l} 
Controlco \\
Yes
\end{tabular}} \\
\hline $\begin{array}{l}\text { P3: } \\
\text { FPp } \\
\text { v } \\
\text { MTS } \\
\end{array}$ & $\begin{array}{l}\text { Ex-stock } \\
\text { availability }\end{array}$ & Not tested & & \\
\hline \multirow{3}{*}{$\begin{array}{l}\text { P4: } \\
\text { FPp } \\
\text { v } \\
\text { MTO }\end{array}$} & $\begin{array}{l}\text { Order lead- } \\
\text { time }\end{array}$ & Yes & Yes & Yes \\
\hline & $\begin{array}{l}\text { Delivery } \\
\text { Reliability }\end{array}$ & No & Yes & Yes \\
\hline & $\begin{array}{l}\text { Demand } \\
\text { Amplification }\end{array}$ & Yes & Yes & Yes \\
\hline
\end{tabular}


Table 7: Cross-case comparison of product modularity and standardization measures ( proposition P5).

\begin{tabular}{|c|c|c|c|c|}
\hline \multirow{2}{*}{\multicolumn{2}{|c|}{$\begin{array}{l}\text { Propositions and } \\
\text { Measure }\end{array}$}} & \multicolumn{3}{|c|}{ Supported } \\
\hline & & \multirow{2}{*}{\begin{tabular}{|l} 
Electrico \\
Yes
\end{tabular}} & \multirow{2}{*}{$\begin{array}{l}\text { Motorco } \\
\text { Yes }\end{array}$} & \multirow{2}{*}{$\begin{array}{l}\text { Controlco } \\
\text { Yes }\end{array}$} \\
\hline $\begin{array}{l}\text { P5: } \\
\text { FPp }\end{array}$ & $\begin{array}{l}\text { Product } \\
\text { standardization }\end{array}$ & & & \\
\hline $\begin{array}{l}\mathbf{v} \\
\text { MTO }\end{array}$ & $\begin{array}{l}\text { Product } \\
\text { Modularity }\end{array}$ & No & No & No \\
\hline
\end{tabular}


Table 8: Cross-case comparison of the excess capacity and throughput efficiency measures related to proposition $\mathbf{P 6}$.

\begin{tabular}{|c|c|c|c|c|}
\hline \multirow{2}{*}{\multicolumn{2}{|c|}{$\begin{array}{l}\text { Propositions and } \\
\text { Measure }\end{array}$}} & \multicolumn{3}{|l|}{ Supported } \\
\hline & & \multirow{2}{*}{$\begin{array}{l}\text { Electrico } \\
\text { No }\end{array}$} & \multirow{2}{*}{$\begin{array}{l}\text { Motorco } \\
\text { Yes }\end{array}$} & \multirow{2}{*}{$\begin{array}{l}\text { Controlco } \\
\text { Yes }\end{array}$} \\
\hline \multirow{2}{*}{ P6: } & $\begin{array}{l}\text { Excess } \\
\text { capacity }\end{array}$ & & & \\
\hline & $\begin{array}{l}\text { Throughput } \\
\text { Efficiency }\end{array}$ & Not tested & Yes & No \\
\hline
\end{tabular}


Table 9: Inventory Management Decision Framework for Unicentric FPp.

\begin{tabular}{|c|c|c|c|c|c|}
\hline \multicolumn{3}{|c|}{ Decision Determinants } & \multirow{2}{*}{$\begin{array}{l}\text { MTO } \\
\text { High }\end{array}$} & \multirow{2}{*}{$\frac{\boldsymbol{F P p}}{\text { High }}$} & \multirow{2}{*}{$\begin{array}{l}\text { MTS } \\
\text { Low }\end{array}$} \\
\hline \multirow{6}{*}{$\begin{array}{l}\text { Product } \\
\text { Demand } \\
\text { Profile }\end{array}$} & \multirow{3}{*}{$\begin{array}{l}\text { End } \\
\text { item } \\
\text { level } \\
\end{array}$} & Product mix & & & \\
\hline & & Demand Variability & High & High & Low \\
\hline & & Volume demand & Low & Low & High \\
\hline & \multirow{3}{*}{$\begin{array}{l}\text { Generic } \\
\text { level }\end{array}$} & Product mix & Medium & Low & Low \\
\hline & & Demand Variability & Medium & Low & Low \\
\hline & & Volume demand & Low & High & High \\
\hline \multirow{3}{*}{\multicolumn{2}{|c|}{ Customer Service }} & Ex-stock availability & $\mathrm{n} / \mathrm{a}$ & High & Medium \\
\hline & & Order lead-time & Long & Short & Short \\
\hline & & Delivery Reliability & Medium & High & $\mathrm{n} / \mathrm{a}$ \\
\hline \multicolumn{3}{|c|}{ Demand amplification } & None & Low & High \\
\hline
\end{tabular}




\section{List of Figures}

Figure 1: Production variety funnels for Controlco's products where EPP keypads are subject to FPp

Figure 2: Framework for the application of FPp. 


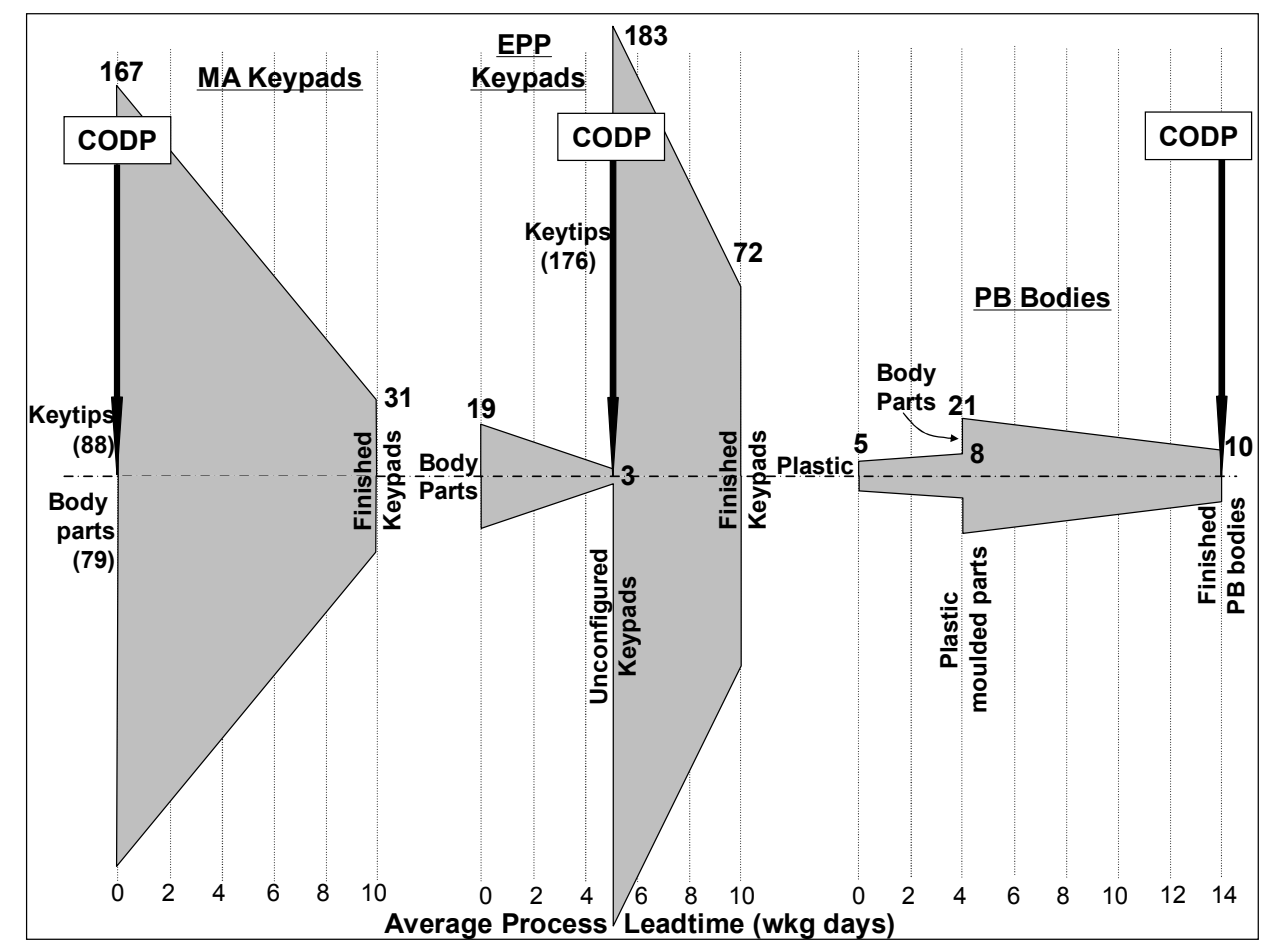




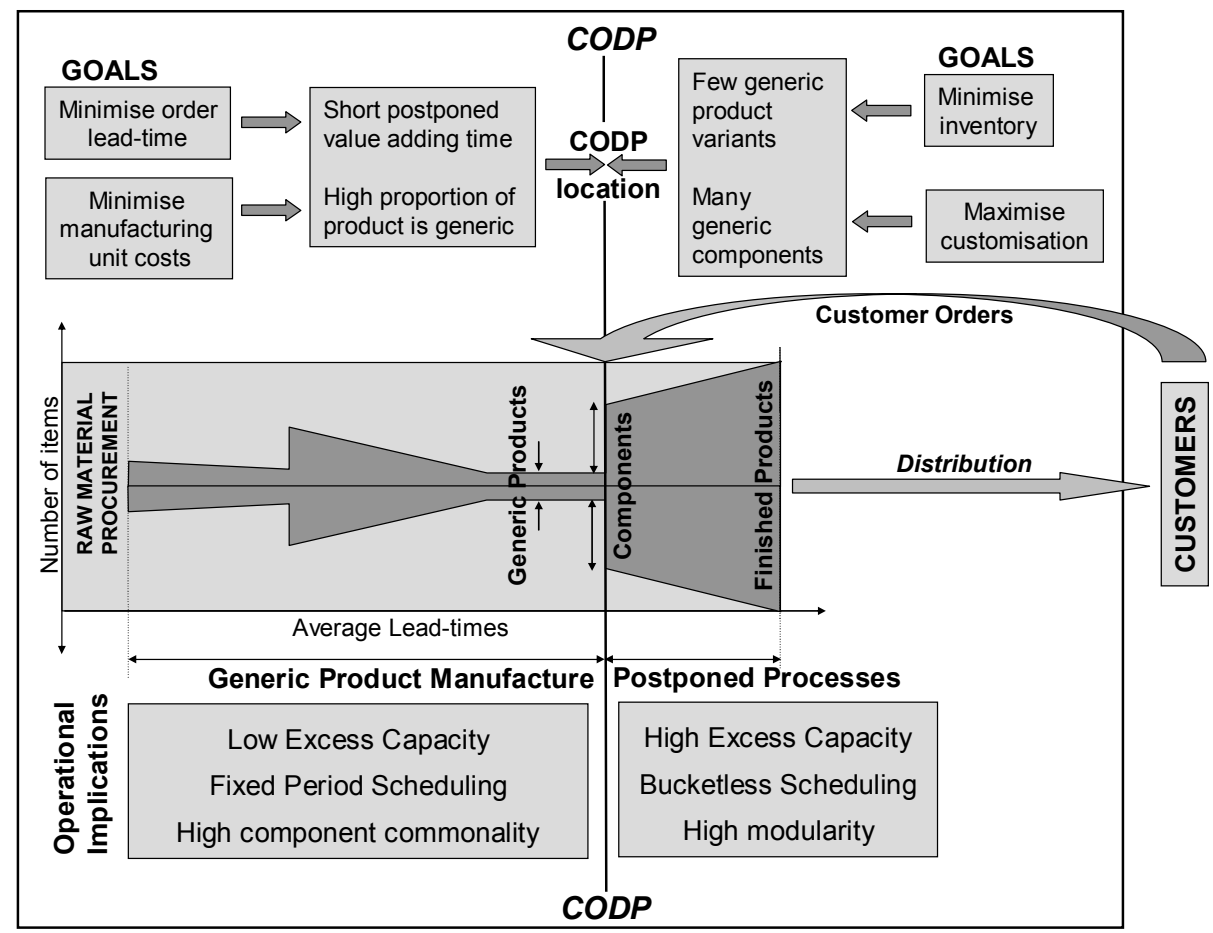

